\title{
Non-Porous Sulfonic Acid Catalysts Derived from Vacuum Residue Asphaltenes for Glycerol Valorization via Ketalization with Acetone
}

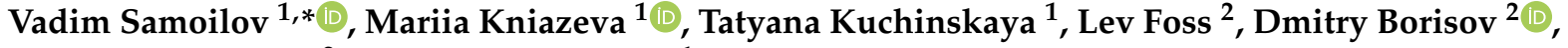 \\ Makhmut Yakubov ${ }^{2}$ and Anton Maximov ${ }^{1}$ \\ 1 A.V. Topchiev Institute of Petrochemical Synthesis, Russian Academy of Sciences (TIPS RAS) 29, \\ Leninsky Prospect, 119991 Moscow, Russia; knyazeva@ips.ac.ru (M.K.); kuchinskaya@ips.ac.ru (T.K.); \\ max@ips.ac.ru (A.M.) \\ 2 Arbuzov Institute of Organic and Physical Chemistry, Kazan Scientific Center, Russian Academy of Sciences, \\ Arbuzov Str. 8, 420088 Kazan, Russia; 1-foss@iopc.ru (L.F.); boriku@gmail.com (D.B.); \\ yakubovmr@mail.ru (M.Y.) \\ * Correspondence: samoilov@ips.ac.ru
}

\section{check for} updates

Citation: Samoilov, V.; Kniazeva, M.; Kuchinskaya, T.; Foss, L.; Borisov, D.; Yakubov, M.; Maximov, A. Non-Porous Sulfonic Acid Catalysts Derived from Vacuum Residue Asphaltenes for Glycerol Valorization via Ketalization with Acetone. Catalysts 2021, 11, 776. https:// doi.org/10.3390/catal11070776

Academic Editors: Francesco Ruffo and Roberto Esposito

Received: 3 June 2021

Accepted: 18 June 2021

Published: 26 June 2021

Publisher's Note: MDPI stays neutral with regard to jurisdictional claims in published maps and institutional affiliations.

Copyright: (c) 2021 by the authors. Licensee MDPI, Basel, Switzerland. This article is an open access article distributed under the terms and conditions of the Creative Commons Attribution (CC BY) license (https:// creativecommons.org/licenses/by/ $4.0 /)$.
Abstract: In this study, an approach for the preparation of heterogeneous acid catalysts based on asphaltenes isolated from vacuum residue is proposed. Varying the conditions for the sulfonation of asphaltenes made it possible to obtain materials with an acid value of 1.16 to 2.76 meq g $^{-1}$ and a total sulfur content of 6.4 to $12.3 \mathrm{wt} \%$. The samples obtained were characterized by acid-base titration, nitrogen adsorption, sulfur elemental analysis and transmission electron microscopy techniques, and were studied as potential acid catalysts in the ketalization reaction between glycerol and acetone. Sulfonated asphaltenes (SA) were characterized by a homogeneous distribution of sulfonic groups over the granule surface and an almost complete absence of a porous structure. The ketalization reaction in the presence of SA proceeded without intradiffusion restrictions; as a result of which, their activity was higher than for known heterogeneous catalysts. The most active SA sample (total acid value, $1.16 \mathrm{meq}^{-1}$ ) had an apparent activation energy of $18.0 \mathrm{~kJ} \mathrm{~mol}^{-1}$, which was lower than the value obtained for the zeolite BEA-40 (29-53 $\left.\mathrm{kJ} \mathrm{mol}^{-1}\right)$ and the Amberlyst 36 resin $\left(27 \mathrm{~kJ} \mathrm{~mol}^{-1}\right)$, and was close to the value for the homogeneous p-TSA catalyst $\left(14.5 \mathrm{~kJ} \mathrm{~mol}^{-1}\right)$. The SA heterogeneous catalysts did not show any acid leaching and had no loss of activity after five catalytic cycles, with the total turnover number $\mathrm{TON}=7247$.

Keywords: glycerol; solketal; asphaltenes; sulfonic acid catalyst; ketalization

\section{Introduction}

Solketal, a cyclic ketal of glycerol and acetone, is one of the most interesting and promising derivatives of bioglycerin. The interest in this compound is due to a number of specific reasons. First, the ketalization reaction as a whole proceeds easily, which means that it can be carried out with low consumption of materials and energy while obtaining high yields of the target substance [1,2]; for synthesis, crude glycerol can be used [3-6]. Secondly, solketal has a number of interesting applications. The industrial use of this compound as a component of green solvents for paints and coatings has been reported [7]. In addition, solketal can be used as a component of biodiesel fuel [8] or automotive gasoline [9-11], and also act as an intermediate for the synthesis of higher acetals and glycerol ketals [12], quinolones via Scraup reaction [13], or in the joint synthesis of isopropanol and propylene glycol via solketal destructive hydrogenolysis [14]. Thirdly, when using renewable raw materials, solketal can have a completely renewable nature.

For the synthesis of solketal by the direct condensation of acetone with glycerol (Scheme 1), a huge number of homogeneous and heterogeneous catalysts of various types have been proposed. 


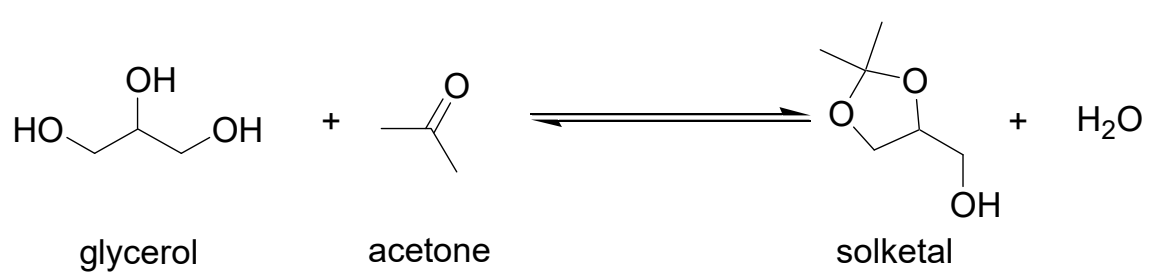

Scheme 1. The reaction scheme of solketal synthesis from glycerol and acetone.

Among the commercially available materials, macroreticular ion exchange acids [15-17], zeolite-based catalysts [18], p-toluenesulfonic [19], and sulfuric acid are often used [1]. Further work in this area, thus, can be roughly divided into two categories. In the first case, the aim of such work should be to develop a catalyst that demonstrates increased activity in the ketalization reaction. Indeed, the nature of the reaction allows its rate to be increased without compromising the quality of the process: the reaction selectivity approaches $100 \%$, and the heat effect of the reaction is very low $[1,20]$. The reduced activity of heterogeneous catalysts compared to homogeneous ones, in the general case, is associated with the presence of diffusion restrictions; therefore, a desire to increase the activity of the catalyst directs scientists towards the synthesis of materials with an extremely developed surface and highly active functional groups with respect to the reaction. For example, Vicente, Melero and the co-authors have obtained catalytically active materials based on the mesoporous silicas with the sulfonic functional groups. The materials' specific surface area values were between 533 and $721 \mathrm{~m}^{2} \mathrm{~g}^{-1}$ and the mean pore size was between 81 and $92 \mathrm{~nm}$. By their activity, the novel materials were comparable with the commercially available ones (with the same functional groups) [21].

The inability to compare the catalytic activity of newly proposed materials with known ones is the main feature of the second category of scientific works concerning the catalytic synthesis of a solketal: in these, this reaction is used as a convenient system for testing the catalytic activity of a new material. The convenience of the reaction as a test system is due to the fact that catalysis in the ketalization reaction is nonspecific, the reaction rate is high, and activity can be detected even for relatively weakly acidic materials (such as montmorillonite K10) [12,22]. For example, Churipard et al. have synthesized mesoporous polymers and, after sulfonation with sulfuric acid, obtained catalytically active materials with specific surface area values between 314 and $363 \mathrm{~m}^{2} \mathrm{~g}^{-1}$ and a mean pore size of $10.6 \mathrm{~nm}$. These materials were highly active in the synthesis of solketal, although they were not compared with other catalysts [23]. A number of studies created with the analogous approach may be found in the scientific literature.

Hence, it should be concluded that the proposed catalysts should demonstrate such a high increase in activity compared to industrial samples that it would justify their use; the corresponding analysis is largely overlooked. Nevertheless, the traditional approach to heterogeneous catalysis is mainly traced: in order to achieve maximum activity, it is necessary to achieve the occurrence of a heterogeneous catalytic reaction in the kinetic region. To eliminate diffusion restrictions, a support is required, the porous structure of which would not create diffusional limitations. It is logical to conclude that the pore size of such a support should not be too small, with a maximally developed inner surface. At the same time, an alternative approach may well have the right to life: the catalyst may not have an inner surface and a porous structure at all, but can conduct a catalytic process due to functional groups localized on the outer surface of the granule. The main question is whether such a catalyst can have a high activity or a level of activity that is at least comparable to the activity of porous catalysts.

In this study, petroleum asphaltenes isolated from vacuum residue are considered as a starting material for the analysis of acid catalysts. Such polyaromatic hydrocarbons are formed in the oil industry as by-products, mainly in tar deasphalting plants; their further disposal is part of the more general problem of heavy oil residues disposal. It was shown earlier that by sulfonating asphaltenes, ion-exchange materials can be obtained that are 
applicable for water treatment [24-26]; some preliminary data on the catalytic properties of these materials were also reported [27]. In this work, the sulfonation of asphaltenes is used as an approach for the preparation of non-porous acid catalysts, as a result of which a set of samples with different sulfonation degrees was obtained. The obtained materials were characterized both by a number of physicochemical methods (acid-base titration, nitrogen adsorption, sulfur elemental analysis and high-resolution transmission electron microscopy with energy dispersive X-ray analysis (HR-TEM/EDX), and in relation to the catalytic activity in the synthesis of solketal, in order to determine the activity of a sulfonated heterogeneous catalyst with no inner surface.

\section{Results and Discussion}

Data on sulfur content and acid value for samples of sulfonated asphaltenes are presented in Table 1 (the samples are called SA- $\tau$, where SA refers to the "sulfonated asphaltene" and $\tau$ to the sulfonation time in minutes). With increasing sulfonation time, the mass fraction of sulfur in the material and its acid value (determined by titrimetry) increase. This dependence is clearly traced between the samples of initial asphaltenes (SA-0) and samples SA-5, SA-10, SA-30 and SA-60. For the SA-30 sample, the mass fraction of sulfur was higher than for the other samples; an analogous pattern of the non-linear dependence between the sulfur content and the sulfonation severity has been observed in our previous studies on asphaltenes sulfonation [24,26]. Further sulfonation (with a contact time of more than $60 \mathrm{~min}$ ) does not lead to a noticeable increase in either the sulfur content or the total acid value of the material. Some additional increase in acid value is achieved with additional sulfonation with oleum within $60 \mathrm{~min}$ after sulfonation with sulfuric acid (sample SA-150/60), although the increase in acid value in this case is disproportionate to the increase in the mass fraction of sulfur. In general, the sulfur content in the sulfonated samples was of the same order of that previously reported by Yakubov for very similar tar-derived materials [25].

Table 1. The main properties of the tested sulfonated asphaltene (SA) catalyst samples.

\begin{tabular}{|c|c|c|c|c|}
\hline $\begin{array}{c}\text { Sample } \\
\text { (Sulfonation Protocol) }\end{array}$ & Acronym & $\begin{array}{l}\text { Sulfur Weight } \\
\text { Content, wt } \%\end{array}$ & $\begin{array}{l}\text { Calculated Total Acid } \\
\text { Number meq } \mathbf{g}^{-1}\end{array}$ & $\begin{array}{l}\text { Titrimetric Total Acid } \\
\text { Number, meq } \mathrm{g}^{-1}\end{array}$ \\
\hline neat asphaltenes & SA-0 & 3.97 & - & 0.30 \\
\hline $\mathrm{H}_{2} \mathrm{SO}_{4}, 5 \mathrm{~min}$ & SA-5 & 6.40 & 1.06 & 1.16 \\
\hline $\mathrm{H}_{2} \mathrm{SO}_{4}, 10 \mathrm{~min}$ & SA-10 & 8.56 & 1.73 & 1.79 \\
\hline $\mathrm{H}_{2} \mathrm{SO}_{4}, 30 \mathrm{~min}$ & SA-30 & 11.27 & 2.58 & 2.38 \\
\hline $\mathrm{H}_{2} \mathrm{SO}_{4}, 60 \mathrm{~min}$ & SA-60 & 9.66 & 2.08 & 2.50 \\
\hline $\mathrm{H}_{2} \mathrm{SO}_{4}, 90 \mathrm{~min}$ & SA-90 & 8.68 & 1.77 & 2.48 \\
\hline $\mathrm{H}_{2} \mathrm{SO}_{4}, 120 \mathrm{~min}$ & SA-120 & 8.91 & 1.84 & 2.41 \\
\hline $\mathrm{H}_{2} \mathrm{SO}_{4}, 150 \mathrm{~min}$ & SA-150 & 9.43 & 2.01 & 2.40 \\
\hline $\mathrm{H}_{2} \mathrm{SO}_{4}, 150 \mathrm{~min}+$ oleum, $60 \mathrm{~min}$ & SA-150/60 & 12.33 & 2.91 & 2.76 \\
\hline
\end{tabular}

Based on the data on the change in the mass fraction between the initial sample of asphaltenes and the sulfonated samples, the calculated acid values were obtained (the calculation was carried out on the assumption that all sulfur introduced into the material was presented in the form of $\mathrm{SO}_{3} \mathrm{H}$ groups). As can be seen in Table 1, in general, the discrepancy between the mean acid value (average of the calculated and the titrimetric values) and the individual values does not exceed $9.2 \mathrm{rel} \%$. The exceptions are samples SA-90 and SA-120, for which the differences in acid value values are 16.7 and 13.4 rel\%, respectively. One should also note that, in fact, not all the sulfur introduced onto the asphaltene matrix is responsible for the acid value [26]. Taking into account the aforementioned consideration, as well as possible overlap in the errors of both analyzes, it can be concluded that the bulk of the sulfur introduced into the material is presented in the form of sulfo groups, which is highly typical for materials of this kind [28]. 
Since granular asphaltenes undergo sulfonation, during processing functional groups can be distributed over the granules both homogeneously and over the surface (the latter option is possible if the sulfonating agent molecules are unable to diffuse into the asphaltene granules). As can be seen from the maps of the distribution of elements over the surface of materials (Figure 1), oxygen and sulfur are uniformly distributed over granules of sulfoasphaltenes, regardless of the degree of sulfonation. Thus, the distribution of sulfo groups over the surface of the granules of the material can be considered homogeneous. The mass fractions of oxygen and sulfur increase with increasing sulfonation time (Figure 2), which correlates with the results of determining the mass fraction of sulfur by the CHNS method (Table 1). The lower mass fraction of sulfur obtained from the EDX method is evidence that this calculation does not include the nitrogen and metals present in petroleum asphaltenes. At the same time, the data on the sulfur content obtained by the EDX method have the same order as the data of the CHNS analysis.

When analyzing samples of sulfonated asphaltenes (SA-5, SA-10, SA-30 and SA-150) by the method of low-temperature nitrogen adsorption, it was found that the surface of the materials was not developed; the specific surface area was about $1.5 \mathrm{~m}^{2} \mathrm{~g}^{-1}$, which agrees with the literature data [29].

For the purpose of comparison, several different acidic catalysts were employed (Table 2).

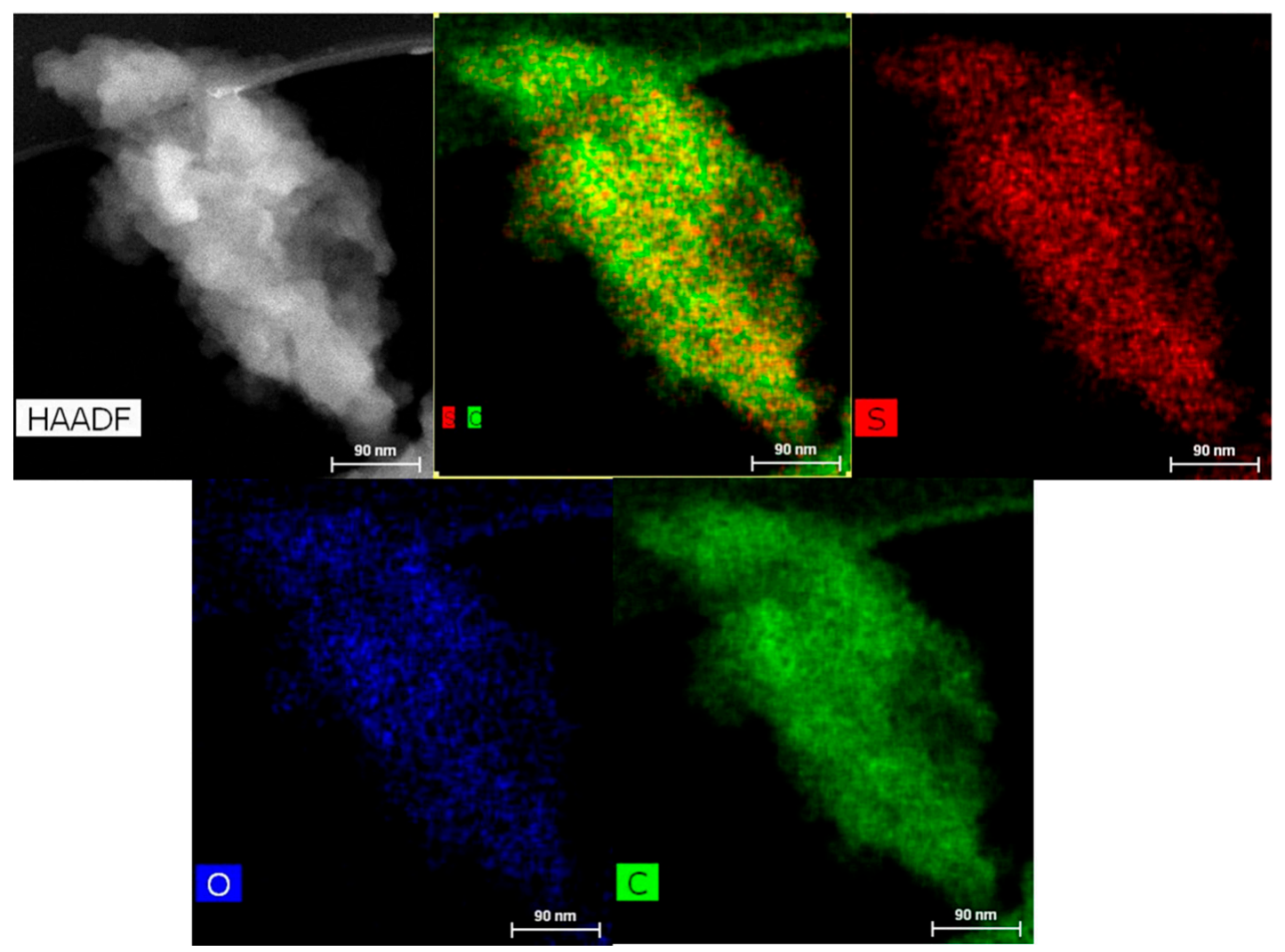

(a)

Figure 1. Cont. 


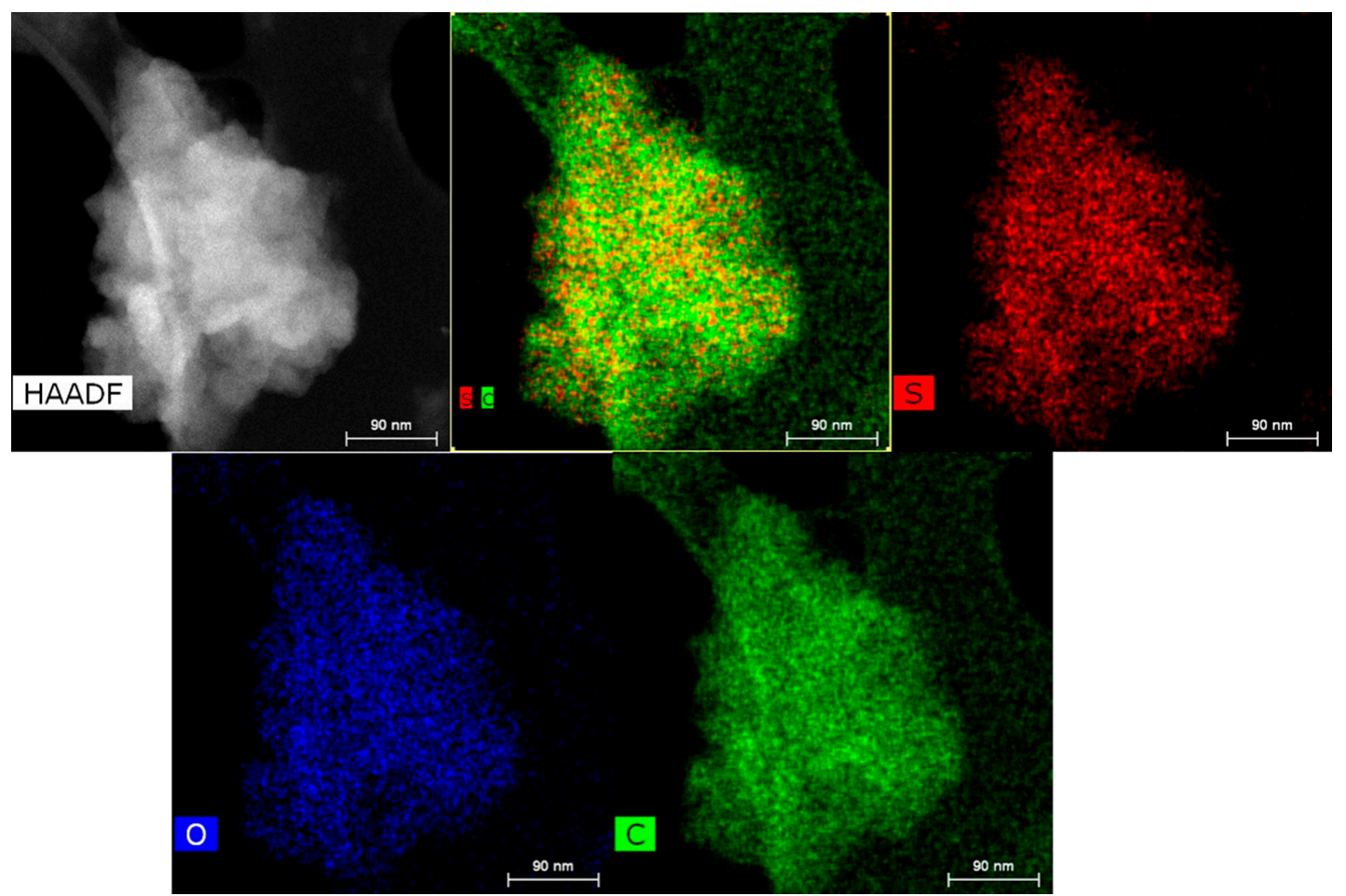

(b)

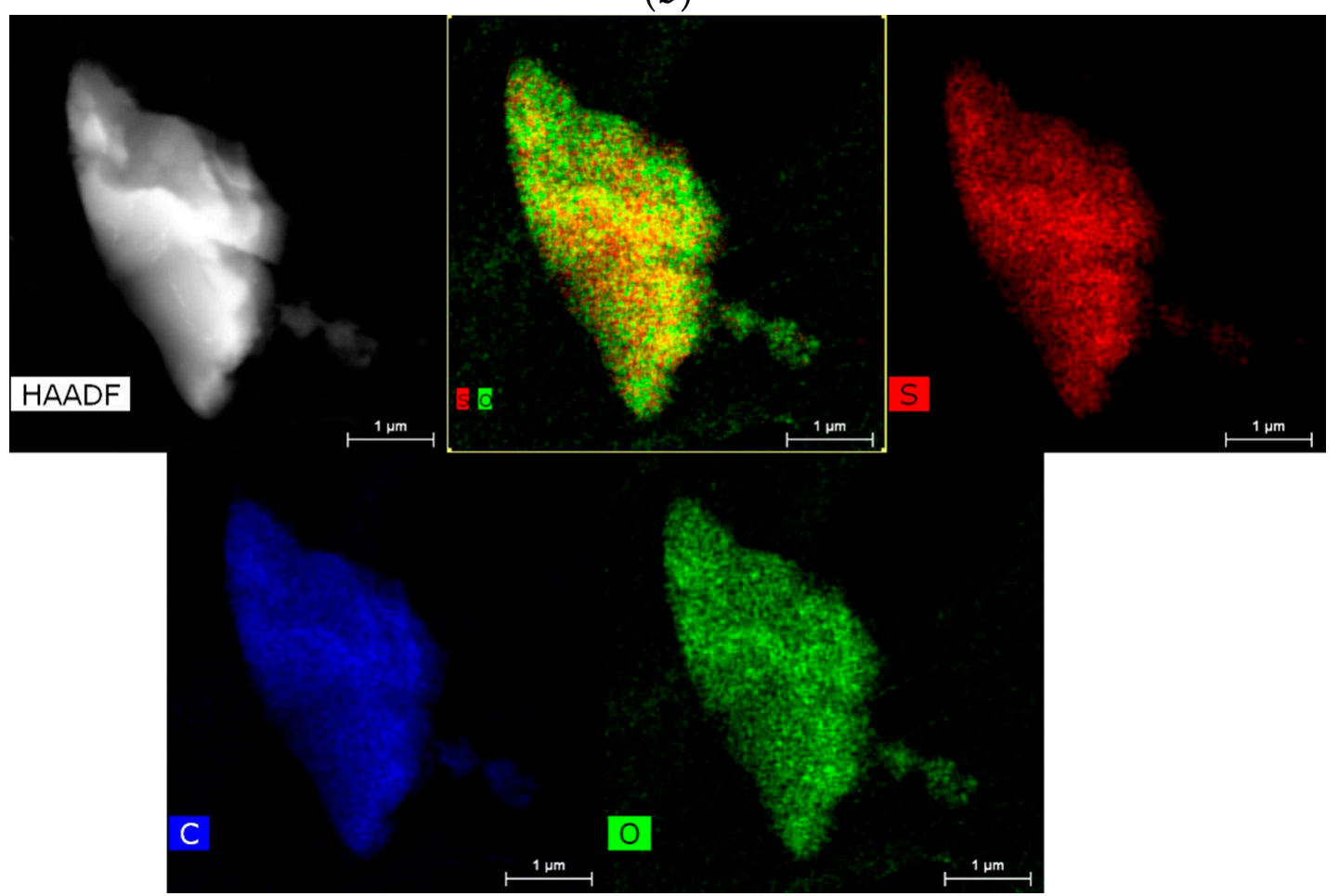

(c)

Figure 1. Cont. 


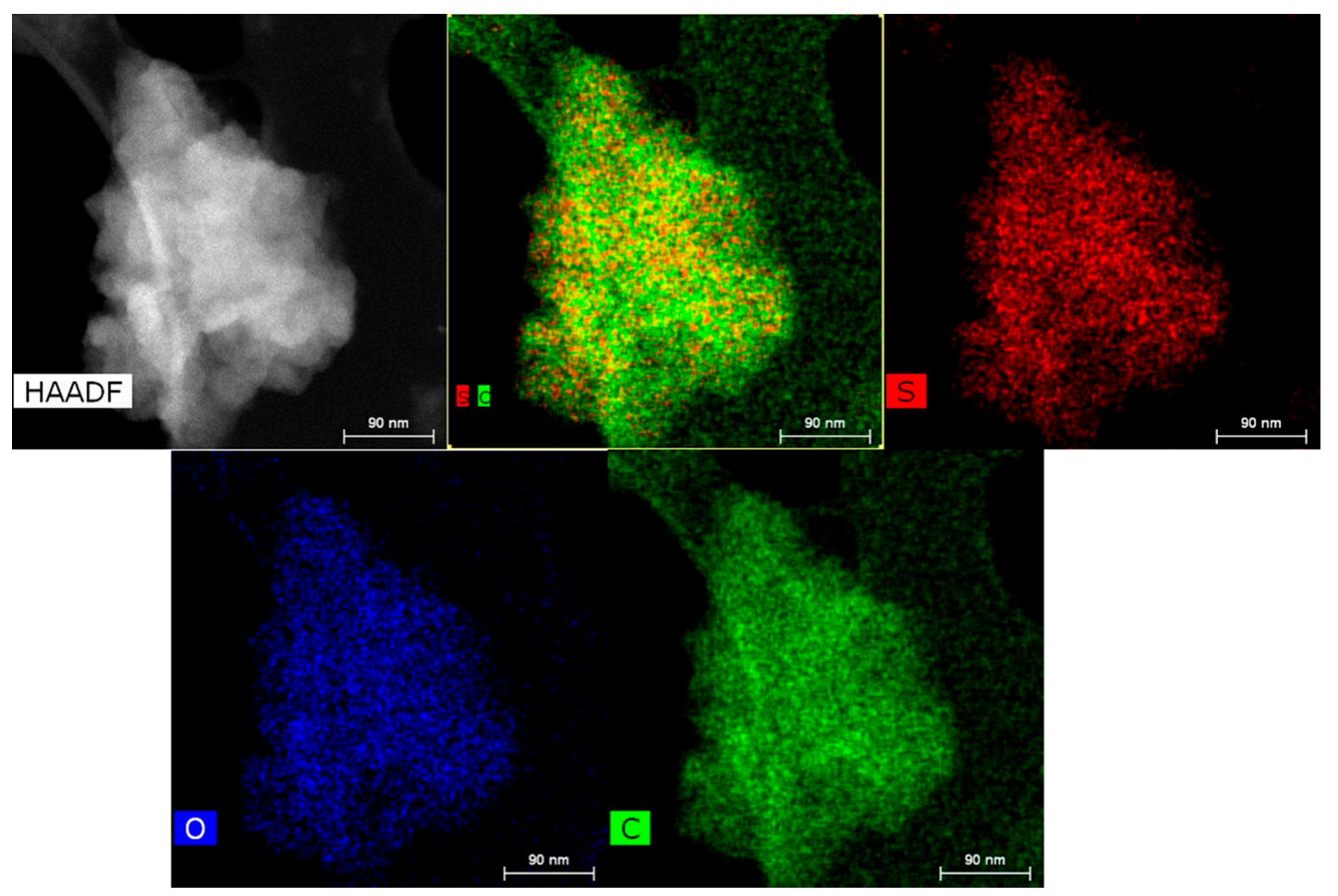

(d)

Figure 1. TEM-EDX mapping microphotographs for the SA samples: (a) SA-5, (b) SA-10, (c) SA-30, (d) SA-150.

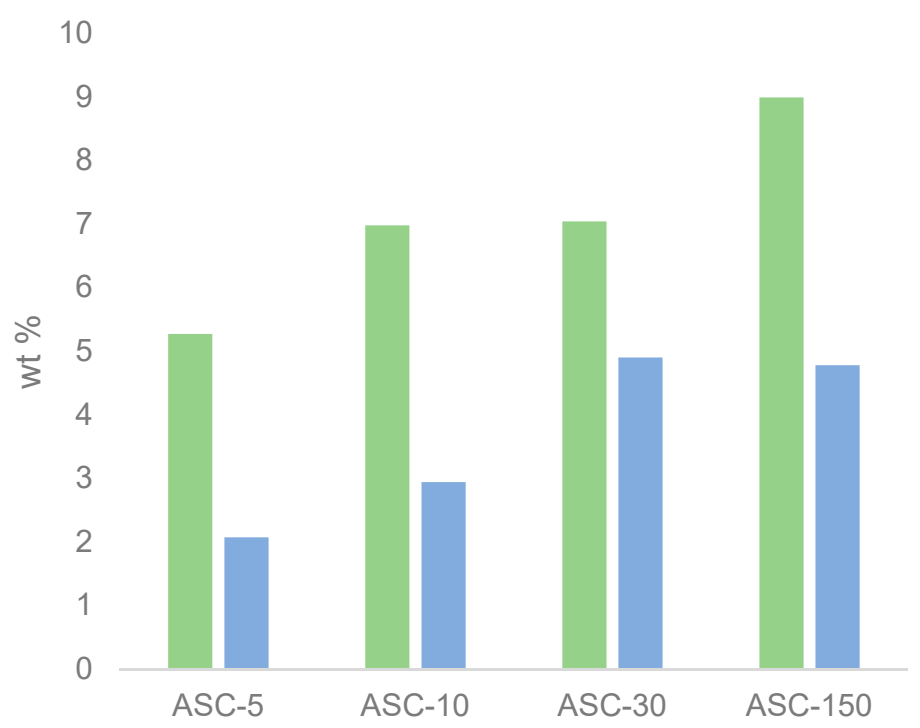

Figure 2. The weight percentage of the sulfur (green) and the oxygen (blue) in the SA samples determined from the TEM-EDX. 
Table 2. The properties of the acidic catalysts used for the comparison with the SA samples.

\begin{tabular}{|c|c|c|c|c|}
\hline Catalyst & Acronym & Total Acid Value, meq $\mathrm{g}^{-1}$ & $\begin{array}{l}\text { Specific SurFace Area, } \\
\qquad \mathrm{m}^{2} \mathrm{~g}^{-1}\end{array}$ & Mean Pore Diameter, nm \\
\hline$p$-toluenesulfonic acid & p-TSA & 5.81 & - & - \\
\hline Amberlyst 36 Dry ${ }^{1}$ & A-36 & 5.10 & 33 & 24 \\
\hline Amberlyst 45 Dry $^{1}$ & A-45 & 2.10 & 49 & 19 \\
\hline Zeolyst CP814 & BEA-25 & 0.86 & 680 & -2 \\
\hline Zeolyst CP811 & BEA-40 & 0.63 & 750 & -2 \\
\hline montmorillonite K10 & K-10 & 0.50 & 264 & 3.8 \\
\hline sulfonated coal & SC & 0.74 & 756 & 2.3 \\
\hline $10 \mathrm{wt} \% \mathrm{~F}-4 \mathrm{SF} / \mathrm{SiO}_{2}$ & $\mathrm{~F}-4 \mathrm{SF} / \mathrm{SiO}_{2}$ & 0.38 & 231 & - \\
\hline Al-HMS (Si / Al = 20) & Al-HMS(20) & 0.17 & 850 & 4.2 \\
\hline
\end{tabular}

${ }^{1}$ The data provided by the manufacturer; ${ }^{2}$ the three-dimensional structure of the materials is characterized by the two pore types with sizes of $0.76 \times 0.64$ and $0.55 \times 0.55 \mathrm{~nm} ;{ }^{3}$ the properties have been previously reported by us for the BEA zeolites and the Al-HMS(20) [30], $\mathrm{K}-10$ [12], SC [31] and the $10 \mathrm{wt} \% \mathrm{~F}-4 \mathrm{SF} / \mathrm{SiO}_{2}[18]$.

As suggested above, the materials under study are granules without pores and inner surfaces and which are sulfonated uniformly along the outer surface. At the same time, if part of the sulfo groups penetrate into the granule during the sulfonation process, then, given the absence of pores, these groups should be less accessible to reagent molecules. A control experiment was carried out on sample SA-60, which was used as a catalyst for the ketalization of glycerol in the form of granules and fine powder. Under the reaction conditions $\left(\mathrm{T}=40^{\circ} \mathrm{C}\right.$, glycerol: $\mathrm{Eq} \mathrm{H} \mathrm{H}^{+}=2500 \mathrm{~mol}$, acetone:glycerol:ethanol = 2:1:1 mol), the glycerol conversion after $60 \mathrm{~min}$ for the granular and powdery catalysts was 58 and $56 \%$, respectively. The close conversion values confirm the assumption that, in sulfonated asphaltenes, active groups are concentrated on the granule surface.

To further compare the activity of different catalysts, a test was carried out to optimize the mixing conditions in the reactor in order to eliminate the possible effect of external diffusion restrictions. At a stirring rate above $1000 \mathrm{rpm}\left(\mathrm{T}=40^{\circ} \mathrm{C}\right.$, glycerol: $\mathrm{Eq} \mathrm{H}^{+}=2500 \mathrm{~mol}$, acetone:glycerol:ethanol $=2: 1: 1 \mathrm{~mol}$ ), the effect of external diffusion on the reaction rate was eliminated (Figure 3). Further experiments were carried out at a stirring speed of $1500 \mathrm{rpm}$.

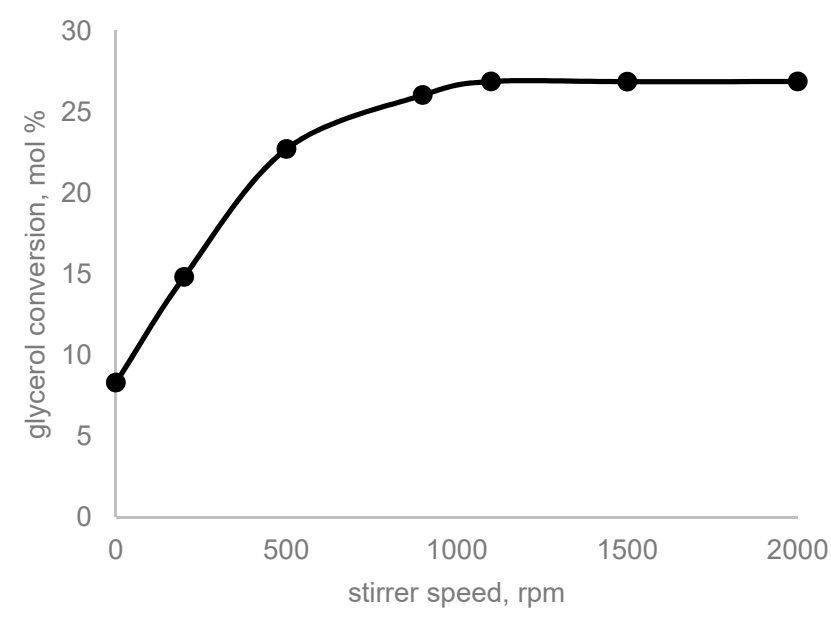

Figure 3. Ketalization of glycerol with acetone $\left(\mathrm{T}=40{ }^{\circ} \mathrm{C}\right.$, glycerol: $\mathrm{Eq} \mathrm{H}^{+}=2500$ mol, acetone:glycerol:ethanol $=2: 1: 1 \mathrm{~mol}$, reaction time $=60 \mathrm{~min}$ ): the dependence of the solketal yield vs the stirrer speed. 
Comparison of the catalytic activity of the known catalysts for glycerol ketalization, in general, led to predictable results. All heterogeneous catalysts were markedly less active than p-TSA, with the exception of the $\mathrm{F}-4 \mathrm{SF} / \mathrm{SiO}_{2}$ (Table 3). The latter circumstance can be explained by the higher acidic strength of the functional groups of this Nafiontype material. A similar effect of the high activity of perfluorosulfonic polymers relative to non-fluorinated catalysts with $\mathrm{SO}_{3} \mathrm{H}$ groups was observed both in the acetalization reaction [32] and in the esterification of glucose with primary alcohols [33]. BEA-40 zeolite was more active than BEA-25, which also correlated with the patterns described earlier [18]. Mesoporous aluminosilicate Al-HMS(20) showed the lowest activity among heterogeneous catalysts, despite its developed porous structure that does not favor diffusional limitations. The activity of sulfonic cation exchanger A-36 was comparable to the activity of p-TSA only at sufficiently high conversion values, while the difference in the values at the initial stage of the reaction indicates a higher activity for homogeneous acid: the solketal yields after $15 \mathrm{~min}$ at $40{ }^{\circ} \mathrm{C}$ were 26.4 and $46.8 \mathrm{~mol} \%$, respectively. It is interesting to note that the activity of sulfonated coal, which has a developed porous structure, was close to that of macroporous sulfcationite: the solketal yield under the same conditions $\left(\mathrm{T}=40^{\circ} \mathrm{C}\right.$, $\tau=15 \mathrm{~min}$ ) was $26.8 \mathrm{~mol} \%$.

Table 3. Comparison of the activity of different catalysts in the ketalization of glycerol with acetone $\left(\mathrm{T}=40{ }^{\circ} \mathrm{C}\right.$, glycerol: Eq $\mathrm{H}^{+}=2500 \mathrm{~mol}$, acetone:glycerol:ethanol = 2:1:1 mol).

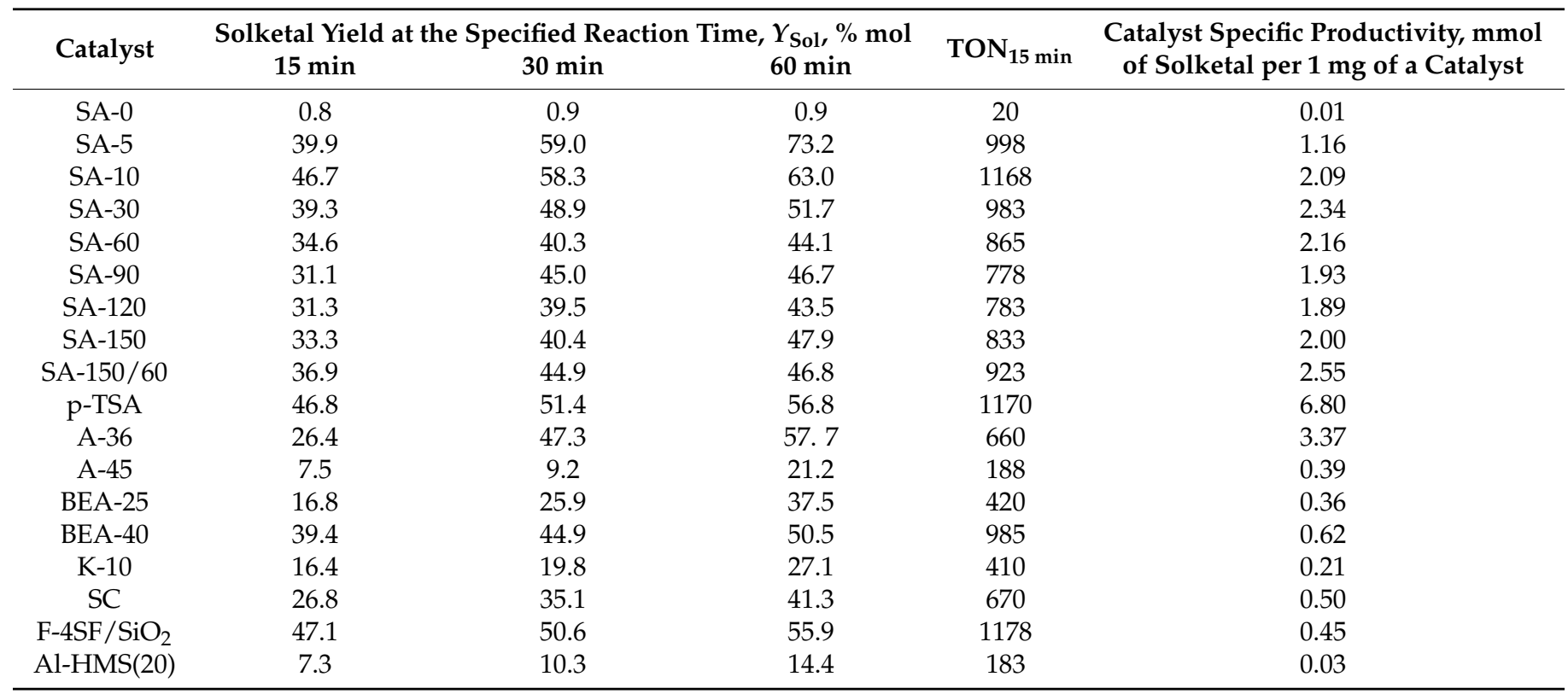

The activity of the sample of unsulfonated asphaltenes SA- 0 in the ketalization reaction was very low: the solketal yield under standard conditions $\left(\mathrm{T}=40^{\circ} \mathrm{C}, \tau=15 \mathrm{~min}\right)$ was $0.8 \mathrm{~mol} \%$, and remained at the same level even when the reaction was continued for up to $60 \mathrm{~min}$. This suggests that the acid value of the initial asphaltene sample was due to the presence of weak acidic groups $(-\mathrm{COOH}, \mathrm{Ph}-\mathrm{OH})$ in the molecular structure, which are capable of catalyzing ketalization at a noticeable rate only at higher temperatures.

All samples of sulfonated asphaltenes showed high activity in relation to the reaction of glycerol ketalization. With an increase in the sulfonation time during the preparation of the catalyst, the activity practically did not change in the series from sample SA-10 to sample SA-150. The highest activity was characteristic of the samples with the minimum sulfonation time: SA-5, SA-10, and SA-30; the solketal yields after 15 min of reaction under standard conditions for these samples were 39.9 and $46.7 \mathrm{~mol} \%$, respectively. The data on the yield of the solketal for $30 \mathrm{~min}$ of the reaction confirm such a distribution of activity between the catalysts. The highest solketal yield (73.2 mol \%) was obtained for the SA-5 catalyst with a reaction time of $60 \mathrm{~min}$, approaching the value of the equilibrium yield [20]; 
such high conversion values no longer allow a correct comparison of the catalyst activity. A further increase in the sulfonation time led to a slight decrease in activity, although in general it remained at the same level: for sample SA-150 (sulfonation with sulfuric acid for $150 \mathrm{~min}$ ), the solketal yield after $15 \mathrm{~min}$ of reaction was $33.3 \mathrm{~mol} \%$. Further sulfonation with oleum (sample SA-150/60), although it led to an increase in the sulfur content in the material, did not allow a significant increase in the catalyst activity: the solketal yield after $15 \mathrm{~min}$ of reaction was $36.9 \mathrm{~mol} \%$, which is slightly less than for catalysts with a low degree of sulfonation. Thus, we can say that the catalysts obtained after short sulfonation times and with a lower surface density of sulfo groups have a higher activity than samples with a higher surface density of sulfo groups: the TON value clearly decreases when going from less sulfonated to more sulfonated samples.

It should be noted that the specific activity of catalysts SA-5, SA-30, and SA-10 approached the activity of a homogeneous acidic catalyst p-TSA with a similar functional group. This circumstance confirms the almost complete absence of intradiffusion restrictions upon catalysis with sulfoasphaltenes, which is in good agreement with the hypothesis put forward earlier that these materials have no inner surface. Thus, the high activity of the proposed materials is explained by the fact that possible intradiffusion restrictions on the reaction rate are eliminated - not by obtaining a material with a developed inner surface, but by completely eliminating the porous structure as such. Of course, at first glance, such an approach seems irrational: it seems that a catalyst operating exclusively on the surface of a granule can never be as efficient as a catalyst with a developed inner surface.

Calculation data for catalyst weight specific productivity after 15 min of reaction (Table 3) show that p-TSA is the most productive catalyst; among heterogeneous catalysts, A-36 has the highest productivity, which is a consequence of the high acid value of this material (about $5.1 \mathrm{meq} \mathrm{g}^{-1}$ ). The specific productivity of other catalysts is significantly lower: even a very active catalyst based on the perfluorosulfopolymer $\mathrm{F}-4 \mathrm{SF} / \mathrm{SiO}_{2}$ has a very low specific productivity $\left(0.45 \mathrm{meq} \mathrm{mg}^{-1}\right)$ due to the low total acid value of the material. It should be noted that the specific weight productivity per unit mass of sulfoasphaltene catalysts ranges between 34 and $69 \%$ of the productivity of sulfonic cation exchanger A-36. Since sulfonation with sulfuric acid, carried out over $60 \mathrm{~min}$, does not significantly increase the acid value of the material, as well as additional sulfonation with oleum, the obtained acid value values can be considered as the maximum achievable for non-porous asphaltene granules. Higher acid values of sulfonic cation exchangers are determined by the more developed matrix surface available for sulfonation. However, given the potential cheapness of the asphaltene-derived acidic materials, they can offer a robust alternative to both the polystyrene-DVB ion-exchange resins and the sulfonated coals.

It should be noted that certain specific productivity values were quite close to the values obtained for the synthesis of solketal in a flow reactor by Dmitriev et al. [1]. Thus, the specific productivity for BEA-40 and A-36 calculated from the solketal yield after $15 \mathrm{~min}$ was 0.69 and $3.74 \mathrm{mmol} \mathrm{s}^{-1} \mathrm{~g}^{-1}$, whereas the corresponding reported values were 1.0 and $3.2 \mathrm{mmol} \mathrm{s}^{-1} \mathrm{~g}^{-1}$, respectively.

To further compare the activity of the catalysts used, kinetic experiments were carried out at reaction temperatures of 30,40 and $50{ }^{\circ} \mathrm{C}$ (reaction time $5 \mathrm{~min}$ ). Based on the data obtained, the level of dependency of the solketal yield on temperature was obtained, from which the values of the apparent activation energy of the reaction were calculated (Table 4). The lowest value of the activation energy $\left(14.5 \mathrm{~kJ} \mathrm{~mol}^{-1}\right)$ was characteristic of the homogeneous p-TSA catalyst. The activation energy of the reaction in the presence of sulfonic cation exchanger A-36 was $27.3 \mathrm{~kJ} \mathrm{~mol}^{-1}$, which is approximately half the value of $55.6 \mathrm{~kJ} \mathrm{~mol}^{-1}$ reported by Nanda et al. for a ketalization reaction under the same conditions and in the presence of A-35 sulfonic cation exchanger with similar properties [20]. This effect, in Nanda et al.'s experiment, can be explained by the possible presence of intradiffusion inhibition, which causes a decrease in the apparent activation energy. Among the heterogeneous catalysts, samples SA-5, SA-30, and SA-150/60 (18.0, 20.5 and $18.1 \mathrm{~kJ} \mathrm{~mol}^{-1}$, respectively) were characterized by the closest values. For the rest of the 
materials from the sulfoasphaltene group, the values ranged from 21.6 to $35.2 \mathrm{~kJ} \mathrm{~mol}^{-1}$. The activation energy for sulfonated carbon (SC), which has the same functional groups as sulfoasphaltenes, but also a well-developed porous structure, was of the same order of magnitude $\left(28.2 \mathrm{~kJ} \mathrm{~mol}^{-1}\right)$. Among other materials, only the $\mathrm{F}-4 \mathrm{SF} / \mathrm{SiO}_{2}$ sample showed a close activation energy $\left(19.6 \mathrm{~kJ} \mathrm{~mol}^{-1}\right)$; in this case, the absence of diffusion restrictions in the developed porous structure of silica gel, in combination with the high catalytic activity of the perfluorosulfopolymer, was probably manifested. Aluminosilicate materials with a well-developed porous structure-zeolites of the BEA type and synthetic aluminosilicate Al-HMS (20) - had lower activity at higher activation energies, which is a consequence of the lower activity of the functional groups of these materials in the ketalization reaction compared to $\mathrm{SO}_{3} \mathrm{H}$ groups.

Table 4. The experimental values of the apparent activation energy in the glycerol ketalization reaction.

\begin{tabular}{cc}
\hline Catalyst & $\mathbf{E}_{\mathbf{a}}, \mathbf{k J} \mathbf{~ m o l}^{\mathbf{- 1}}$ \\
\hline SA-0 & 49.4 \\
SA-5 & 18.0 \\
SA-10 & 35.2 \\
SA-30 & 20.5 \\
SA-60 & 24.6 \\
SA-90 & 24.6 \\
SA-120 & 21.6 \\
SA-150 & 25.5 \\
SA-150/60 & 18.1 \\
p-TSA & 14.5 \\
A-36 & 27.3 \\
A-45 & 139.5 \\
BEA-25 & 53.4 \\
BEA-40 & 28.7 \\
K-10 & 65.6 \\
SC & 28.2 \\
F-4SF/SiO & 19.6 \\
Al-HMS(20) & 65.7 \\
\hline
\end{tabular}

For carbonaceous heterogeneous catalysts possessing the $\mathrm{SO}_{3} \mathrm{H}$ functional groups, the Hammett function usually amounts to $-8 \leq H_{0} \leq-11$ (comparable with the value for the concentrated $\mathrm{H}_{2} \mathrm{SO}_{4}$ ) [28]; the same region of the $H_{0}$ values is reported for the Amberlyst 15 sulfonic cation exchange resin, the $\mathrm{H}_{2} \mathrm{SO}_{4}$-treated $\mathrm{SiO}_{2}$ and $\mathrm{TiO}_{2}$, and for the homogeneous xylene sulfonic acid [34]. Based on these data, one could assume that the similarity of the functional groups of the sulfonated asphaltenes, sulfonated charcoal, Amberlyst 15 and the p-TSA allows one to suppose that their $H_{0}$ functions are close to the aforementioned range. It is also known that the acid strength of Nafion-type materials is close to that of sulfuric acid $\left(H_{0} \approx-12\right)$, so these catalysts with close activation energy values (18-30 $\mathrm{kJ} \mathrm{mol}^{-1}$ ) could be assumed to have similar acid strengths. However, the experimental determination of the acid strength for the sulfonated asphaltene samples remains of interest.

For materials with $\mathrm{SO}_{3} \mathrm{H}$ groups on a carbon carrier, the acid leaching phenomenon is often characteristic, accompanied by a partial loss of material activity. To assess the stability of the sulfoasphaltenes obtained in this study, a control experiment was carried out with a sample of SA-150 asphaltenes (Figure 4). A portion of the catalyst (taken into the reaction in the form of granules) was separated from the reaction mixture after $60 \mathrm{~min}$ of reaction, and the reaction mixture was returned to the same reactor, after which the monitoring of the reaction progress was continued. The solketal yield in the mixture immediately before the separation of the catalyst was $44.6 \%$; an hour after the reaction mixture was returned to the reactor, the yield was $44.8 \%$. The absence of significant differences in the solketal yields allows us to conclude that there was no noticeable acid leaching in the specified conditions. 


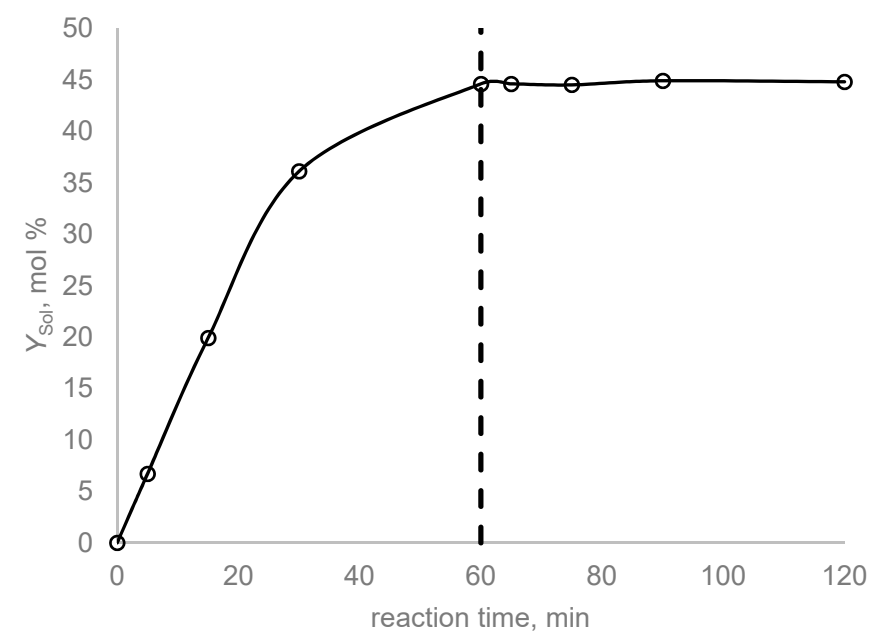

Figure 4. - Ketalization of glycerol with acetone over a sulfonated asphaltene catalyst-the acid leaching test time curve $\left(\mathrm{T}=40^{\circ} \mathrm{C}\right.$, glycerol: $\mathrm{Eq} \mathrm{H}^{+}=2500 \mathrm{~mol}$, acetone:glycerol:ethanol = 2:1:1 mol, catalyst-SA-150).

Since acidic catalysts based on sulfonated asphaltenes demonstrated high activity and specific productivity per unit weight in the glycerol ketalization reaction, in order to further assess the applicability of these materials as acetalization catalysts, their resistance to deactivation under reaction conditions was then assessed.

The reusability test carried out for this showed that the activity of the SA-150 catalyst slightly increased in each subsequent catalytic cycle, exceeding the initial value by 1.2 times in the fifth cycle (Figure 5). Only in the sixth cycle was a slight relative decrease in activity (compared to the foregoing cycle) detected, although its value was still at the level of 1.14 from the value of the first cycle. Thus, the activity of the catalyst did not decrease below the initial one, at least upon reaching the total turnover number (TON) of 7247. The acid value determined for the spent catalyst isolated from the sixth cycle $\left(2.32 \mathrm{meq} \mathrm{g}^{-1}\right)$ indicates that no substantial deactivation of the $\mathrm{SO}_{3} \mathrm{H}$ groups took place during the test (the deviation between the acid values of the fresh and the spent SA-150 samples was about $3.3 \mathrm{rel} \%$ ). This suggests a sufficiently high resistance of the catalyst to deactivation under the conditions of the glycerol ketalization reaction with acetone.

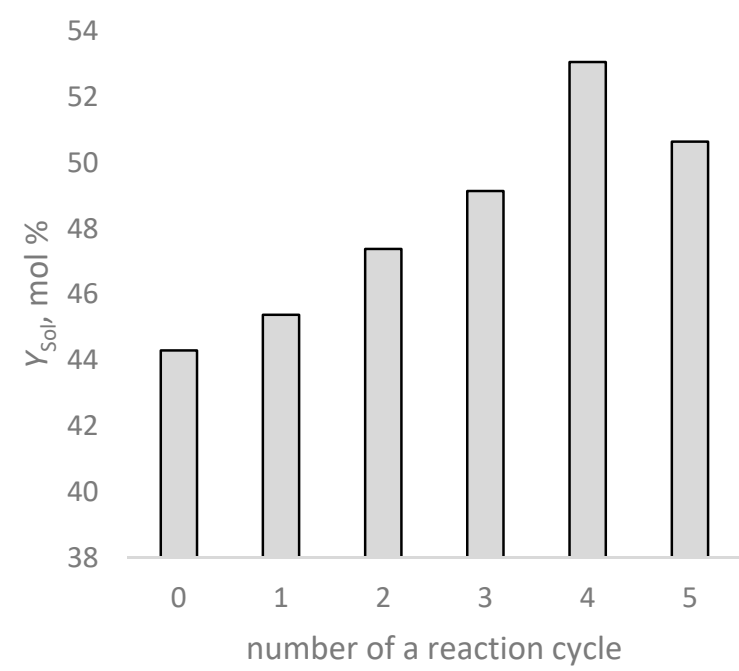

Figure 5. - Ketalization of glycerol with acetone over a sulfonated asphaltene catalyst-the catalyst reusability test $\left(\mathrm{T}=40^{\circ} \mathrm{C}\right.$, glycerol: $\mathrm{Eq} \mathrm{H} \mathrm{H}^{+}=2500 \mathrm{~mol}$, acetone:glycerol:ethanol $=2: 1: 1 \mathrm{~mol}$, catalystSA-150). 


\section{Materials and Methods}

\subsection{Reagents}

For the catalytic tests, glycerol and acetone (analytical grade, Komponent-Reaktiv, Moscow, Russia) were used without any other purification. Ethanol added to reaction mixtures for homogenization (analytical grade, Komponent-Reaktiv, Moscow, Russia) was absolutized over metallic sodium and stored over the 3A molecular sieves. The standard feed reaction mixture (acetone:ethanol:glycerol $=1: 2: 1 \mathrm{~mol}$ ) was prepared once and stored over the 3A molecular sieves to preserve it from possible water accumulation. For the treatment of the reaction mixture aliquots taken out of the reactor, sodium carbonate $\left(\mathrm{Na}_{2} \mathrm{CO}_{3}\right)$ was used (Komponent-Reaktiv, Moscow, Russia).

For the GC quantification method, butanol-1 (analytical grade, Komponent-Reaktiv, Moscow, Russia) was used as an internal standard without any additional purification.

For the synthesis of the sulfonated asphaltenes, sulfuric acid (95.6\%, Sigma Aldrich, St. Louis, MO, USA) and oleum (30\%, Sigma-Aldrich, St. Louis, MO, USA) were used as the sulfonating agents.

\subsection{Catalysts}

Commercially available p-toluenesulfonic acid (p-TSA, reagent grade, KomponentReaktiv, Moscow, Russia), ion-exchange resins Amberlyst 36 Dry and Amberlyst 45 Dry (samples were kindly provided for testing by Dow Europe $\mathrm{GmbH}$, Moscow, Russia), zeolites CP814 (BEA-25) and CP811 (BEA-40) (Zeolyst International, Kansas City, Kansas, USA), montmorillonite K-10 (Acros, Antwerpen, Belgium) were used in the catalytic tests. Prior to use, montmorillonite granules were grained to give a disperse powder and calcined in air at $300{ }^{\circ} \mathrm{C}$. The sulfonic acid cation exchange resins were used without further preparation. The zeolites were calcined at $550{ }^{\circ} \mathrm{C}$ for $10 \mathrm{~h}$ before use.

The syntheses and the characterization procedures of the lab-prepared catalysts have been reported elsewhere for the mesoporous aluminosilica Al-HMS (20) with the $\mathrm{Si} / \mathrm{Al}=20$ [30], the $\mathrm{SiO}_{2}$-supported $\mathrm{F}-4 \mathrm{SF}$ perfluoropolymer (10 $\mathrm{wt} \%$ of the supported polymer) [18] and the sulfonated coal [31].

The asphaltenes were isolated from the vacuum residue (JSC Taneko, Nizhnekamsk, Russia) in accordance with the ASTM D4124-09 procedure [26]. The asphatlenes sulfonation was performed in accordance with the following procedure: to $140 \mathrm{~g}$ of sulfuric acid, $7 \mathrm{~g}$ of asphaltenes (0.4-0.5 mm fraction) were added under continuous stirring. The reaction was further run in a round-bottomed flask equipped with a reflux condenser under the temperature of $80{ }^{\circ} \mathrm{C}$ for $5,10,30,60,90,120$ and $150 \mathrm{~min}$. Upon the completion of the reaction, the reaction mixture was diluted with $9 \mathrm{~L}$ of distilled water. The solid precipitate was vacuum filtered and washed with distilled water until neutral reaction.

The additional treatment with oleum was performed as follows: after 150 min of the reaction with sulfuric acid, $70 \mathrm{~mL}$ of oleum was added dropwise during the following $40 \mathrm{~min}$. After that, stirring was continued for $1 \mathrm{~h}$ and then the sulfonated material was recovered in a similar manner.

\subsection{Catalysts Characterization}

The total acid value of the sulfonated coals was determined by the titrimetric method: sulfonated coal $(0.5 \mathrm{~g})$ was reacted with $50 \mathrm{~mL}$ of a $0.1 \mathrm{M}$ aqueous solution of sodium hydroxide, after which the $\mathrm{NaOH}$ content in the resulting solution was determined by titration with a $0.1 \mathrm{M}$ hydrochloric acid solution (two parallel experiments) with phenolphthalein.

The characteristics of the porous structure were evaluated by the analysis of lowtemperature nitrogen adsorption (ASAP 2020, Micromeritics, Norcross, GA, USA).

The sulfur content in the original asphaltenes and the obtained sulfonated samples were determined by the CHNS analysis (Thermo Flash 2000 analyzer, Waltham, MA, USA).

The sulfonated asphaltenes samples were characterized by means of a high resolution transmission electron microscopy (TEM). For transmission electron microscopy, a FEI 
Tecnai Osiris TEM (FEI Company, Hillsboro, OR, USA) with an accelerating voltage of $200 \mathrm{keV}$ was used. For the SA samples, EDX mapping microphotographs were obtained.

\subsection{Experimental Procedure}

The experiments of the ketalization of glycerol with acetone under atmospheric pressure were carried out in a glass reactor (internal volume, $20 \mathrm{~cm}^{3}$ ) equipped with a thermostating jacket and a reflux condenser. The previously prepared feed reaction mixture (glycerol:acetone:ethanol = 1:2:1 mol) was used. A magnetic stir bar and the reactant mixture $(7 \mathrm{~mL})$ were placed in the reactor and the thermostat was turned on. After reaching the set temperature $\left(30,40\right.$ or $\left.50{ }^{\circ} \mathrm{C}\right)$, a catalyst charge was introduced into the reactor. The catalyst amount was calculated for each catalyst with respect to its total acid value $\left(\mathrm{mmol} \mathrm{g}^{-1}\right)$ in order to maintain the equal molar ratio between the total amount of glycerol and the catalyst acid sites (glycerol: $\mathrm{Eq} \mathrm{H}^{+}=2500 \mathrm{~mol}$ ) in every experimental run. The catalyst introduction moment was taken as the initial reaction time. Stirring was periodically terminated to take aliquots of a $0.05-0.1 \mathrm{~mL}$ volume, which were 'quenched' with two drops of a saturated sodium carbonate water solution and then analyzed by GLC.

The following sampling protocol was applied: each run was repeated twice; each sample was analyzed either 2 or 3 times to obtain the appropriate standard deviation (about $0.5-0.8 \mathrm{~mol} \%$ of the solketal yield).

The leaching test was performed for the SA-150 sample (glycerol:Eq $\mathrm{H}^{+}=2500 \mathrm{~mol}$ ) at $40{ }^{\circ} \mathrm{C}$. The reaction progress was monitored at 5, 15, 30 and $60 \mathrm{~min}$ of the reaction time, and then the catalyst was separated from the reaction mixture via vacuum filtration, while the reactor was quickly flushed with acetone in order to remove the remaining catalyst particles. The filtered reaction mixture was returned to the reactor, the stirring was turned on, and the reaction progress was further monitored via GC.

The reusability test was performed for the SA-150 sample (glycerol:Eq $\mathrm{H}^{+}=2500 \mathrm{~mol}$ ) at $40{ }^{\circ} \mathrm{C}$ in 6 repeating runs (reaction time, $60 \mathrm{~min}$ ). After each run, the catalyst was separated from the reaction mixture by centrifugation, thoroughly washed with acetone, and dried in argon. The amount of the spent catalyst (via weighing) and of the reaction mixture (via dosing by volume) taken for the next run were calculated to provide the same feed-to-catalyst ratio.

The reaction mixture composition was analyzed with the use of the GC-FID ('Kristalluks4000M' gas chromatograph, Meta-Khrom, Yoshkar-Ola, Russia) equipped with a 'Restek Rtx-Wax' $60 \mathrm{~m} / 0.53 \mathrm{~mm} / 1.00 \mu \mathrm{m}$ column (Restek, Bellefonte, PA, USA), and helium as the carrier gas. Butanol-1 (analytical grade, Komponent-Reaktiv, Moscow, Russia) was used as the internal standard for the quantification.

\section{Conclusions}

In the present study, samples of heterogeneous catalysts based on sulfonated asphaltenes isolated from vacuum residue were obtained and characterized. The separated asphaltenes were sulfonated with sulfuric acid at a contact time of 5 to $150 \mathrm{~min}$. With an increase in the sulfonation time to $60 \mathrm{~min}$, an increase in the acid value of the material (from 1.06 to $2.58 \mathrm{mmol} \mathrm{g}^{-1}$ ) and the total sulfur content (from $3.97 \mathrm{wt} \%$ for the initial asphaltenes to $11.27 \mathrm{wt} \%$ for the most sulfonated sample) was observed. A further increase in acid value (up to $2.91 \mathrm{mmol} \mathrm{g}^{-1}$ ) could be achieved by additional sulfonation with oleum for $60 \mathrm{~min}$.

The characterization of the obtained materials by the HR-TEM method showed that the $\mathrm{SO}_{3} \mathrm{H}$ groups introduced at the sulfonation stage were uniformly distributed over the surface of the sulfoasphaltene granules. The specific surface area of sulfoasphaltenes determined by the method of low-temperature nitrogen adsorption did not exceed $1.67 \mathrm{~m}^{2} \mathrm{~g}^{-1}$, which suggested the almost complete absence of an internal porous structure. Thus, the resulting material consisted of monolithic granules without internal pores, sulfonated evenly over the external surface. This assumption was confirmed by the absence of a difference in catalytic activity between the catalyst in the form of granules and in the form of a fine powder. 
The activity of catalysts based on sulfonated asphaltenes in the solketal synthesis reaction was determined and compared with the activity of other acidic catalysts. The highest activity values were characteristic of the least sulfonated samples, SA-5 and SA-10, as well as for the additionally sulfonated sample SA-150/60 with oleum: the values of TON at the reaction time of 15 min were 998, 1168 and 923, respectively. A higher specific activity was recorded only for the homogeneous catalyst p-TSA $\left(\mathrm{TON}_{15}=1170\right)$ and the heterogeneous catalyst based on the perfluorosulfopolymer $\mathrm{F}-4 \mathrm{SF} / \mathrm{SiO}_{2}\left(\mathrm{TON}_{15}=1178\right)$. The activity of such well-known heterogeneous catalysts as BEA-40 zeolite and the montmorillonite K-10 was somewhat lower ( $\mathrm{TON}_{15}=660,985$ and 410, respectively). Sulfonated carbon with a developed porous structure and $-\mathrm{SO}_{3} \mathrm{H}$-functional groups had the same specific activity $\left(\mathrm{TON}_{15}=670\right)$, as styrene-DVB sulfonic cation exchange resin 'Amberlyst $36^{\prime}\left(\mathrm{TON}_{15}=660\right)$.

The catalysts were also compared in terms of the specific productivity per unit mass of the material for $15 \mathrm{~min}$ of reaction. The most productive heterogeneous catalyst was found to be Amberlyst $36\left(3.37 \mathrm{mmol} \mathrm{g}^{-1}\right)$. The productivity of the sulfoasphaltene catalysts reached $2.55 \mathrm{mmol} \mathrm{g}^{-1}$ for sample SA-150/60, additionally sulfonated with oleum, which was $75 \%$ of the productivity of the polymeric ion exchanger. The productivity of the remaining heterogeneous catalysts did not exceed $0.62 \mathrm{mmol} \mathrm{g}^{-1}$. The high activity of the sulfoasphaltene catalysts was also confirmed by calculating the values of the apparent activation energy: the value of $E_{a}$ ranged from 18.0 to $25.5 \mathrm{~kJ} \mathrm{~mol}^{-1}$ for the sulfoasphaltene catalysts, which was lower than the values for zeolite BEA-40 $\left(28.7 \mathrm{~kJ} \mathrm{~mol}^{-1}\right)$ and sulfonic ion exchange resin Amberlyst $36\left(27.3 \mathrm{~kJ} \mathrm{~mol}^{-1}\right)$, and approaches the value obtained for a homogeneous catalytic reaction in the presence of p-TSA $\left(14.5 \mathrm{~kJ} \mathrm{~mol}^{-1}\right)$. The SA150 catalyst based on sulfonated asphaltenes showed the absence of acid leaching and deactivation until reaching a total TON $=7247$ within six reaction cycles.

Taking into account the good catalytic properties of the considered materials and their wide availability, they can be considered as potential catalysts for the synthesis of solketal or homologous acetals by the acid-catalytic condensation of carbonyl compounds with alcohols.

Author Contributions: Conceptualization, M.Y. and A.M.; methodology, V.S, M.K., L.F. and D.B.; investigation, V.S, M.K., T.K., L.F. and D.B.; writing-original draft preparation, V.S.; supervision, A.M.; project administration, M.Y. and A.M. All authors have read and agreed to the published version of the manuscript.

Funding: This research received no external funding.

Acknowledgments: The work has been carried out in frames of the State Program of TIPS RAS (the study on the SA catalytic properties). The work has been carried out in frames of the State Program of the Kazan Scientific Center (the SA synthesis).

Conflicts of Interest: The authors declare no conflict of interest.

\section{References}

1. Dmitriev, G.S.; Terekhov, A.V.; Zanaveskin, L.N.; Khadzhiev, S.N.; Zanaveskin, K.L.; Maksimov, A.L. Choice of a catalyst and technological scheme for synthesis of solketal. Russ. J. Appl. Chem. 2016, 89, 1619-1624. [CrossRef]

2. Nanda, M.R.; Yuan, Z.; Qin, W.; Ghaziaskar, H.S.; Poirier, M.A.; Xu, C. Catalytic conversion of glycerol to oxygenated fuel additive in a continuous flow reactor: Process optimization. Fuel 2014, 128, 113-119. [CrossRef]

3. Dmitriev, G.S.; Zanaveskin, L.N.; Terekhov, A.V.; Samoilov, V.O.; Kozlovskii, I.A.; Maksimov, A.L. Technologies for Processing of Crude Glycerol from Biodiesel Production: Synthesis of Solketal and Its Hydrolysis to Obtain Pure Glycerol. Russ. J. Appl. Chem. 2018, 91, 1478-1485. [CrossRef]

4. Guidi, S.; Noè, M.; Riello, P.; Perosa, A.; Selva, M. Towards a rational design of a continuous-flow method for the acetalization of crude glycerol: Scope and limitations of commercial amberlyst 36 and AlF3.3H2O as model catalysts. Molecules 2016, 21, 657. [CrossRef]

5. Kowalska-Kuś, J.; Held, A.; Nowińska, K. A continuous-flow process for the acetalization of crude glycerol with acetone on zeolite catalysts. Chem. Eng. J. 2020, 401, 126143. [CrossRef]

6. Talebian-Kiakalaieh, A.; Tarighi, S. Hierarchical faujasite zeolite-supported heteropoly acid catalyst for acetalization of crudeglycerol to fuel additives. J. Ind. Eng. Chem. 2019, 79, 452-464. [CrossRef]

7. Solvay Augeo. Available online: http://www.solvay.com/en/brands/augeo (accessed on 24 June 2021). 
8. Melero, J.A.; Vicente, G.; Morales, G.; Paniagua, M.; Bustamante, J. Oxygenated compounds derived from glycerol for biodiesel formulation: Influence on EN 14214 quality parameters. Fuel 2010, 89, 2011-2018. [CrossRef]

9. Mota, C.J.A.; Da Silva, C.X.A.; Rosenbach, N.; Costa, J.; Da Silva, F. Glycerin derivatives as fuel additives: The addition of glycerol/acetone ketal (solketal) in gasolines. Energy Fuels 2010, 24, 2733-2736. [CrossRef]

10. Alptekin, E.; Canakci, M. Performance and Emission Characteristics of Solketal-Gasoline Fuel Blend in a Vehicle With Spark Ignition Engine. Appl. Therm. Eng. 2017, 124, 504-509. [CrossRef]

11. Samoilov, V.O.; Maximov, A.L.; Stolonogova, T.I.; Chernysheva, E.A.; Kapustin, V.M.; Karpunina, A.O. Glycerol to renewable fuel oxygenates. Part I: Comparison between solketal and its methyl ether. Fuel 2019, 249, 486-495. [CrossRef]

12. Samoilov, V.O.; Ni, D.S.; Maximov, A.L. Transacetalization of Solketal: A Greener Route to Bioglycerol-Based Speciality Chemicals. ChemistrySelect 2018, 3, 9759-9766. [CrossRef]

13. Jin, J.; Guidi, S.; Abada, Z.; Amara, Z.; Selva, M.; George, M.W.; Poliakoff, M. Continuous niobium phosphate catalysed Skraup reaction for quinoline synthesis from solketal. Green Chem. 2017, 19, 2439-2447. [CrossRef]

14. Samoilov, V.O.; Ni, D.S.; Dmitriev, G.S.; Zanaveskin, L.N.; Maximov, A.L. The Joint Synthesis of 1,2-Propylene Glycol and Isopropyl Alcohol by the Copper-Catalyzed Hydrogenolysis of Solketal. ACS Sustain. Chem. Eng. 2019, 7, 9330-9341. [CrossRef]

15. Nanda, M.R.; Yuan, Z.; Qin, W.; Ghaziaskar, H.S.; Poirier, M.A.; Xu, C.C. A new continuous-flow process for catalytic conversion of glycerol to oxygenated fuel additive: Catalyst screening. Appl. Energy 2014, 123, 75-81. [CrossRef]

16. Dmitriev, G.S.; Terekhov, A.V.; Khadzhiev, S.N.; Zanaveskin, L.N. Specific features of solketal synthesis on KU-2-8 cation-exchange resin. Russ. J. Appl. Chem. 2016, 89, 45-50. [CrossRef]

17. Esteban, J.; Ladero, M.; García-Ochoa, F. Kinetic modelling of the solventless synthesis of solketal with a sulphonic ion exchange resin. Chem. Eng. J. 2015, 269, 194-202. [CrossRef]

18. Maksimov, A.L.; Nekhaev, A.I.; Shlyakhtitsev, D.S.; Varfolomeev, S.D.; Vol'eva, V.B.; Nikiforov, G.A. Synthesis of the components of engine fuels on the basis of renewable raw materials: Trends and prospects. Pet. Chem. 2010, 50, 325-331. [CrossRef]

19. Da Silva, C.X.A.; Gonçalves, V.L.C.; Mota, C.J.A. Water-tolerant zeolite catalyst for the acetalisation of glycerol. Green Chem. 2009, 11, 38. [CrossRef]

20. Nanda, M.R.; Yuan, Z.; Qin, W.; Ghaziaskar, H.S.; Poirier, M.A.; Xu, C.C. Thermodynamic and kinetic studies of a catalytic process to convert glycerol into solketal as an oxygenated fuel additive. Fuel 2014, 117, 470-477. [CrossRef]

21. Vicente, G.; Melero, J.; Morales, G.; Paniagua, M.; Martín, E. Acetalisation of bio-glycerol with acetone to produce solketal over sulfonic mesostructured silicas. Green Chem. 2010, 12, 899. [CrossRef]

22. Maximov, A.L.; Nekhaev, A.I.; Ramazanov, D.N. Ethers and acetals, promising petrochemicals from renewable sources. Pet. Chem. 2015, 55, 1-21. [CrossRef]

23. Churipard, S.; Manjunathan, P.; Chandra, P.; Shanbhag, G.; Ravishankar, R.; Rao, P.V.C.; Sri Ganesh, G.; Halgeri, A.B.; Maradur, S.P. Remarkable catalytic activity of a sulfonated mesoporous polymer (MP-SO3H) for the synthesis of solketal at room temperature. New J. Chem. 2017, 41, 5745-5751. [CrossRef]

24. Yakubov, M.R.; Gryaznov, P.I.; Abilova, G.R.; Yakubova, S.G.; Ivanov, V.T.; Milordov, D.V.; Mironov, N.A. Effect of synthesis conditions of asphaltene sulfocationites on their composition and sorbtion properties. Indian J. Sci. Technol. 2015, 8, 1-6. [CrossRef]

25. Yakubov, M.R.; Gryaznov, P.I.; Yakubova, S.G.; Sinyashin, K.O.; Milordov, D.V.; Mironov, N.A. Composition and sorption properties of asphaltene sulfonates. Pet. Sci. Technol. 2017, 35, 2152-2157. [CrossRef]

26. Yakubov, M.R.; Gryaznov, P.I.; Yakubova, S.G.; Tazeeva, E.G.; Mironov, N.A.; Milordov, D.V. Structural-group composition and properties of heavy oil asphaltenes modified with sulfuric acid. Pet. Sci. Technol. 2016, 34, 1805-1811. [CrossRef]

27. Foss, L.E.; Shabalin, K.V.; Musin, L.I.; Nagornova, O.A.; Salikhov, R.Z.; Borisov, D.N.; Musin, R.Z.; Yakubov, M.R. Synthesis of Asphaltene-Based Strongly Acidic Sulfonated Cation Exchangers and Determination of Their Catalytic Properties in the 2,2-Dimethyl-1,3-Dioxolane Synthesis Reaction. Pet. Chem. 2020, 60, 709-715. [CrossRef]

28. Konwar, L.J.; Mäki-Arvela, P.; Mikkola, J.P. SO3H-Containing Functional Carbon Materials: Synthesis, Structure, and Acid Catalysis. Chem. Rev. 2019, 119, 11576-11630. [CrossRef] [PubMed]

29. Parkash, S.; Moschopedis, S.; Speight, J. Physical properties and surface characteristics of asphaltenes. Fuel 1979, 58, 877-882. [CrossRef]

30. Samoilov, V.; Onishchenko, M.; Ramazanov, D.; Maximov, A. Glycerol isopropyl ethers: Direct synthesis from alcohols and synthesis by the reduction of solketal. Chem CatChem 2017, 9, 2839-2849. [CrossRef]

31. Samoilov, V.O.; Ni, D.S.; Goncharova, A.V.; Knyazeva, M.I.; Ramazanov, D.N.; Maksimov, A.L. Catalytic hydrogenolysis of solketal on bifunctional catalysts with production of high octane components of motor fuels. Russ. J. Appl. Chem. 2020, 93, 108-117. [CrossRef]

32. Frusteri, F.; Spadaro, L.; Beatrice, C.; Guido, C. Oxygenated additives production for diesel engine emission improvement. Chem. Eng. J. 2007, 134, 239-245. [CrossRef]

33. Karam, A.; De Oliveira Vigier, K.; Marinkovic, S.; Estrine, B.; Oldani, C.; Jérôme, F. High Catalytic Performance of Aquivion PFSA, a Reusable Solid Perfluorosulfonic Acid Polymer, in the Biphasic Glycosylation of Glucose with Fatty Alcohols. ACS Catal. 2017, 7, 2990-2997. [CrossRef]

34. Marczewski, M.; Aleksandrowicz, M.; Brzezińska, E.; Podlewska, M.; Rychlik, M.; Żmuda, S.; Ulkowska, U.; Gliński, M.; Osawaru, O. Acid strength measurements of Amberlyst 15 resin, p-xylene-2-sulfonic acid and chlorosulfonic and sulfuric acid treated SiO2, Al2O3, TiO2 and MgO. React. Kinet. Mech. Catal. 2019, 126, 1081-1096. [CrossRef] 